\title{
Nakkesmerter med og uten nerverotsaffeksjon
}

\author{
Sammendrag \\ Bakgrunn. Nakkesmerter er utbredt \\ i befolkningen. Prevalensen er 30-50\%, \\ høyest blant kvinner og mennesker \\ i yrkesaktiv alder. Nakkesmerter og \\ andre muskel- og skjelettplager er en \\ av de vanligste årsakene til langtidssyk- \\ melding og uføretrygd i Norge, noe som \\ understreker behovet for enhetlige ret- \\ ningslinjer for diagnostikk, utredning og \\ behandling av denne pasientgruppen.
}

Materiale og metode. Artikkelen er basert på en gjennomgang av The Bone and Joint Decade 2000-2010, Task Force on Neck Pain and Its Associated Disorder, på Cohrane-oversikter og supplerende referanser ut fra kjennskap til området.

Resultater. Det er foreslått en inndeling av nakkesmerter etter alvorlighetsgrad (grad 1-4) som et verktøy i daglig klinisk praksis. De uspesifikke nakkesmertene (grad 1 og grad 2) er fortsatt en utfordring, og det er usikker kunnskap om hvilke tilstander som kan ligge bak. Diagnostikk og utredning av nakkesmerter er først og fremst rettet mot å utelukke nerverotsaffeksjon (grad 3) eller alvorlig sykdom i nakken (grad 4).

Fortolkning. Mangelen på publikasjoner av høy kvalitet innen feltet gjør behandling av nakkesmerter krevende, på grunn av lite støtte for valg av én behandlingsmodalitetet fremfor en annen. Det er stort behov for mer forskning på området, og dette bør prioriteres nasjonalt.

\section{Øystein P. Nygaard}

oystein.nygaard@ntnu.no

Nasjonalt senter for spinale lidelser

Nevrokirurgisk avdeling

St. Olavs hospital

Postboks 3250 Sluppen

7006 Trondheim

og

Institutt for nevromedisin

Det medisinske fakultet

Norges teknisk-naturvitenskapelige universitet

Magne Rø

Nasjonalt senter for spinale lidelser

Avdeling for fysikalsk medisin og rehabilitering

St. Olavs hospital

og

Institutt for nevromedisin

Det medisinske fakultet

Norges teknisk-naturvitenskapelige universitet

Tor Inge Andersen

Nasjonalt senter for spinale lidelser

St. Olavs hospital

og

Trondheim fysikalske institutt

John-Anker Zwart

Nasjonalt senter for spinale lidelser

St. Olavs hospital

og

Nevrologisk avdeling

Oslo universitetssykehus

Nakkesmerter og andre muskel- og skjelettplager er utbredt i befolkningen. Dette er bakgrunnen for at Verdens helseorganisasjon (WHO) definerte tiåret 2000-10 som The Bone and Joint Decade (1). En av gruppene som ble nedsatt for å gå igjennom kunnskapen om temaet nakkesmerter var Task Force on Neck Pain and Its Associated Disorders (2). I et av deres arbeider oppsummeres forekomsten av nakkesmerter i den generelle befolkningen. Ettårsprevalensen ligger et sted mellom $30 \%$ og $50 \%$ pga. ulikheter i definisjon og metode (3). Dette er i samsvar med studier fra Norge (4-6). Imidlertid er andelen som i det daglige plages av nakkesmerter eller rapporterer sammenhengende nakkesmerter av mer enn tre måneders varighet siste år omkring 20 \% (5, 6). Det er gjennomgående høyere prevalens og insidens av nakkesmerter blant kvinner og blant mennesker i yrkesaktiv alder (3-7).

Smerter i nakken og andre muskel- og skjelettplager er en av de hyppigste årsakene til langtidssykmelding og uføretrygd i Norge (8). Således er det viktig med korrekt diagnostikk og håndtering av denne pasientgruppen. Det foreligger i dag ingen nasjo- nale eller internasjonale retningslinjer for behandling av pasienter med nakkesmerter tilsvarende det som finnes for pasienter med smerter lavt i korsryggen. Formålet med denne oversiktsartikkelen er å gi oppdaterte kunnskapsbaserte, tverrfaglige anbefalinger om diagnostikk og behandling av denne store pasientgruppen. Pasienter med traumatisk utløst nakkesmerte (kronisk nakkeslengssyndrom) omtales ikke her.

\section{Materiale og metode}

Artikkelen bygger vesentlig på The Bone and Joint Decade 2000-2010, Task Force on Neck Pain and Its Associated Disorders (2, 9-11). Cochrane-oversikter publisert frem til juli 2009 er også gjenomgått, og det er tatt med supplerende referanser ut fra kjennskap til emneområdet. Artikkelforfatterne har alle mangeårig klinisk og forskningsmessig erfaring innen feltet.

\section{Inndeling og diagnostikk}

Task Force on Neck Pain and Its Associated Disorders har foreslått en inndeling av nakkesmerter etter alvorlighetsgrad (tab 1) som et verktøy i daglig klinisk praksis (9). God anamnese og grundig klinisk undersøkelse vil avdekke om det foreligger tegn på nerverotsaffeksjon (grad 3) eller andre alvorlige patologiske tilstander ( $\operatorname{grad} 4)$. I tabell 2 (9) er det en oversikt over «røde flagg» som indikasjon på alvorlig skade - til hjelp i diagnostikken. I de fleste tilfeller vil det imidlertid ikke være

\section{Hovedbudskap}

- Nakkesmerter kan inndeles i grad 1-4 etter alvorlighetsgrad

- Diagnostikk og utredning er først og fremst rettet mot å utelukke nerverotsaffeksjon (grad 3) eller alvorlig sykdom i nakken (grad 4)

- Det finnes ingen gode data som understøtter rangert anbefaling av behandlingsalternativer ved nakkesmerter uten nerverotsaffeksjon

- Trening sammen med leddmobilisering/manipulasjon har vist god effekt i behandling av nakkesmerter uten nerverotsaffeksjon

- Vi anbefaler henvisning til MR-undersøkelse ved nakkesmerter med nerverotsaffeksjon av varighet over 4-6 uker 
holdepunkter for alvorlige patologiske forhold. Tilstanden benevnes da uspesifikke nakkesmerter og kategoriseres i grad 1 eller grad 2 ut fra i hvilken grad den fører til funksjonsnedsettelse i dagliglivet (9).

Med grad 3-skade har pasienten nakkesmerter og symptomer eller tegn på nerverotsaffeksjon. Dette er forårsaket av cervikal spondylose, noe som fører til kompresjon av nerveroten på grunn av prolaps fra mellomvirvelskiven eller trange forhold i nerverotskanalen. Sannsynligvis foreligger det også et element av inflammasjon i tillegg til kompresjon av nerveroten. De cervikale prolapsene er, i motsetning til de lumbale, oftest lokalisert lateralt og komprimerer nerveroten idet den er på vei ut av nerverotskanalen. Over $90 \%$ av prolapsene er lokalisert til skivene $\mathrm{C} 5 / \mathrm{C} 6$ og C6/C7 (11-13).

\section{Klinisk undersøkelse}

Et viktig mål med anamnesen er å få oversikt over psykososiale forhold som kan ha betydning for prognosen og dempe eventuelle bekymringer hos pasienten om at det kan foreligge alvorlig skade. Den kliniske undersøkelsen er bedre egnet til å utelukke nerverotsaffeksjon (grad 3) eller alvorlige patologiske tilstander ( $\operatorname{grad} 4)$ enn til å stille spesifikke diagnoser (2). En god klinisk undersøkelse innbefatter inspeksjon, testing av aktiv og passiv bevegelighet, palpasjon og provokasjonstester samt nevrologisk undersøkelse med Spurlings test for å kartlegge eventuell cervikal nerverotsaffeksjon (fig 1) (14).

Ved bevegelighetstesting kan pasientens hastighet si noe om vedkommendes frykt for å røre seg. Man kan også forsøke å få et inntrykk av om nedsatt bevegelighet hovedsakelig skyldes stram muskulatur eller vertebrogen dysfunksjon. Ved test på sidefleksjon i nakken kan draget på m. trapezius øvre del slakkes ved at man passivt løfter skulderbuen. Dersom dette fører til økt sidefleksjon, er det en indikasjon på at den innskrenkede bevegelsen er muskulært betinget. Palpasjon av triggerpunkter og ømme punkter (tender points) skiller dårlig mellom ulike former av nakkelidelser, men kan si noe om i hvilken grad det er et muskulært element i plagene. Utbredelsen av muskulær ømhet vil gi opplysninger om hvorvidt smertene er lokaliserte eller generaliserte. Det er rapportert at pasienter med langvarige nakkesmerter kan få endring i de nevromuskulære kontrollmekanismene og koordinasjonen uavhengig av patoanatomisk årsak til plagene $(15,16)$.

Det er utviklet standardiserte undersøkelsesmetoder for å kartlegge muskulær kontroll, noe mange fysioterapeuter benytter seg av. Nakkesmerter lokalisert i øvre del av nakken kan bli referert til bakhodet, mens smerter i nedre del av nakken ofte refereres til interskapulærregionen, skuldre og armer (17). Differensialdiagnostisk er det viktig å skille plager som er skulderutløst fra nakkesmerter som gir utstråling til skulder. Det er derfor viktig å utføre en vanlig skulderunder-

Tabell 1 Inndeling av nakkesmerter etter alvorlighetsgrad (9)
Grad 1 Ingen tegn til alvorlige patologiske forandringer og liten eller ingen innvirkning på dagliglivets funksjon
Grad 2 Ingen tegn på alvorlige patologiske forandringer, men sikker nedsatt funksjon i dagliglivet
Grad 3 Tegn på nerverotsaffeksjon/radikulopati
Grad 4 Tegn på alvorlige patologiske forandringer som brudd, myelopati, neoplasme, infeksjon eller systemiske sykdommer

Tabell 2 Røde flagg som gir mistanke om alvorlig underliggende årsak til nakkesmerter (9)

Traumer Pasienter med osteoporose og de som har brukt kortikosteroider kan få brudd selv etter små traumer

Malignitet Pasienter med kreftdiagnose eller der det er progredierende vekttap eller tiltakende symptomer over en måned

Myelopati Sensoriske og motoriske symptomer i armer eller bein med affeksjon av gangfunksjonen

Infeksjoner Pasienter med uttalte lokaliserte smerter med lokal palpasjonsømhet over én eller flere virvler. Intravenøst stoffmisbruk er en disponerende faktor

Systemiske lidelser Ankyloserende spondylitt eller andre revmatiske lidelser gir allmennsymptomer og funn ved supplerende prøver

søkelse hos pasienter der årsaken til nakkesmertene er uklar. Den hyppigste årsak til skulderutløste smerter er subakromial impingement-syndrom av ulike årsaker (18), men man må også tenke på at kapsulitt, tendinopatier, akromioklavikulærleddsaffeksjon og andre patologiske tilstander i skulderen kan gi smerter i nakkeområdet. Smerter fra akromioklavikulærleddet blir referert til supraklavikulært område. Andre aktuelle differensialdiagnostiske overveielser er nevralgisk skulderamyotrofi, pleksopatier og perifere nevropatier, som vil kunne bekreftes ved supplerende nevrofysiologiske undersøkelser.

Cervikal nerverotsaffeksjon kan gi forskjellig symptombilde alt etter hvilke nervestrukturer som påvirkes. Smerter i nakke/ skulder/arm er vanligvis det dominerende symptom, mens nummenhet og parestesier i overekstremitetene er de vanligste sensoriske symptomer. Smerteutbredelsen følger ikke nødvendigvis dermatomgrensene, men kan være mer diffust lokalisert i armen. Dersom det foreligger motoriske utfall, er dette vanligvis i form av lette til moderate pareser. Smertene kan ofte provoseres frem mekanisk. Ekstensjon i nakken, lateralfleksjon og rotasjon mot symptomsiden og aksialt trykk mot hodet vil kunne forsterke smerten ned i armen (Spurlings test) (fig 1) og er godt egnet til å avdekke nerverotspåvirkning (14). Denne testen har gode egenskaper og bør benyttes regelmessig hos pasienter med utstrålende smerter i overekstremitetene (19). Bruk av selektive blokader mot fasettledd og nerverøtter kan gi en viss diagnostisk støtte, men må utføres av kompetent personell.

Den cervikale spondylosen kan også føre til affeksjon av selve ryggmargen (cervikal myelopati). Pasientene vil da vanligvis ha lite nakkesmerter, men symptomer i form av nummenhet, klossethet og styringsvansker i over- eller underekstremitetene. Ved den kliniske undersøkelsen vil man kunne påvise tegn på affeksjon av det sentrale nervesystem (dårlig gangfunksjon, hyperrefleksi, invertert plantarrefleks og spastisitet).

\section{Henvisning}

Pasienter med uspesifikke nakkesmerter kan tas hånd om av primærhelsetjenesten (fig 2). De bør opprettholde vanlig aktivitet og få informasjon om at dette sannsynligvis er en forbigående smerte. Manglende bedring etter 4-6 uker er i seg selv ingen sterk indi-

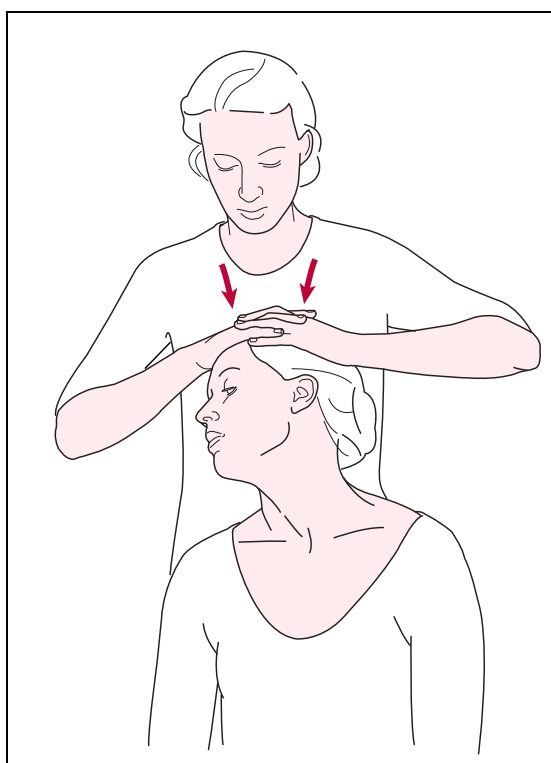

Figur 1 Spurlings test. Ekstensjon i nakken, lateralfleksjon og rotasjon mot aktuell side kombinert med aksialt trykk vil kunne forsterke smertene ned i armen (14) 
kasjon for henvisning til bildediagnostikk (MR), dette bør vurderes ut fra symptomenes intensitet. Der det er uttalte smerter og manglende bedring av tilstanden i løpet av 2-3 måneder, bør pasienten henvises til spesialistutredning. Ved mistanke om nerverotsaffeksjon hos pasienter med uttalte smerter anbefaler vi MR-undersøkelse dersom det ikke er tegn til bedring etter 4-6 uker. Dette er den beste undersøkelsesmodaliteten, gir gode bilder av nerverotskanalen og vil kunne vise prolaps eller rotkanalstenose. Dersom det på MR-undersøkelsen er tegn til nerverotskompresjon og pasienten fortsatt har mye smerter, anbefales henvisning til spesialist. Ved klinisk mistanke om røde flagg skal vedkommende raskt henvises videre til MR-undersøkelse og spesialistvurdering ( $\operatorname{tab} 2)$.

\section{Behandling og tiltak}

\section{Ikke mistenkt nerverotsaffeksjon}

Det er i første rekke pasienter med nakkesmerte grad 2 som er aktuelle for rehabiliteringstiltak. Valg av behandlingsstrategi må baseres på den kliniske undersøkelsen. En helhetlig tilnærming rettet mot følgene av det å ha en smertetilstand vil være hensiktsmessig. Slike følgetilstander kan være funksjonsnedsettelse, unngåelsesatferd og sosial dysfunksjon. Undervisning og holdningspåvirkning er en del av de fleste systematiske oppfølgingsprogrammer, men slik multidisiplinær biopsykososial rehabilitering er dårlig dokumentert både når det gjelder å få til smertereduksjon og fremme bedre funksjon (20).

Trening og øvelser har vist seg å ha effekt ved både akutte og langvarige nakkesmerter, og behandling der man legger vekt på tidlig aktivisering er mest effektiv (10). Det er imidlertid ikke vist at noen spesielle treningsmetoder eller øvelser er bedre enn andre. Derfor bør valg av behandling tilpasses den enkelte pasient. Kombinasjon av øvelser og manuell leddmobilisering/manipulasjon har effekt ved både akutte og langvarige nakkesmerter $(10,21,22)$. Spesifikke nakkeøvelser i den hensikt å bedre den nevromuskulære kontrollen har vist lovende resultater i flere studier og kan forsøkes der målet er bedre funksjon $(21,23)$. Akupunktur har vist seg å ha noe effekt ved korttidsobservasjon (3 md.) $(10,24)$. Det samme gjelder lavdosert laserterapi mot triggerpunkter i nakken, der det er vist positiv korttidseffekt ( $3 \mathrm{md}$.) i to randomiserte studier $(10,25)$.

Det finnes i dag ingen indikasjon for operativ behandling av isolerte nakkesmerter uten nerverotsaffeksjon. Radiofrekvensbehandling ved ensidige nakkesmerter hos pasienter som har god effekt av selektiv blokade av fasettledd, mangler fortsatt god vitenskapelig dokumentasjon.

Det er ingen robuste data som understøtter rangert anbefaling av de ulike behandlingsalternativer som foreligger $(10,20,26)$. Behandlingen bør tilpasses den enkelte pasient. Det er imidlertid en rekke ulike faktorer som det må tas hensyn til når det gjelder forventet effekt av behandlingen (27). Prognosen er knyttet til kjønn, alder og genetisk disposisjon hos pasienten samt en rekke livsstilsfaktorer og type arbeid (27-29). Nakkesmerter kan ha sammenheng med andre muskel- og skjelettplager, hodepine (30), psykisk helse og sosiale forhold (28). Utbredte plager er

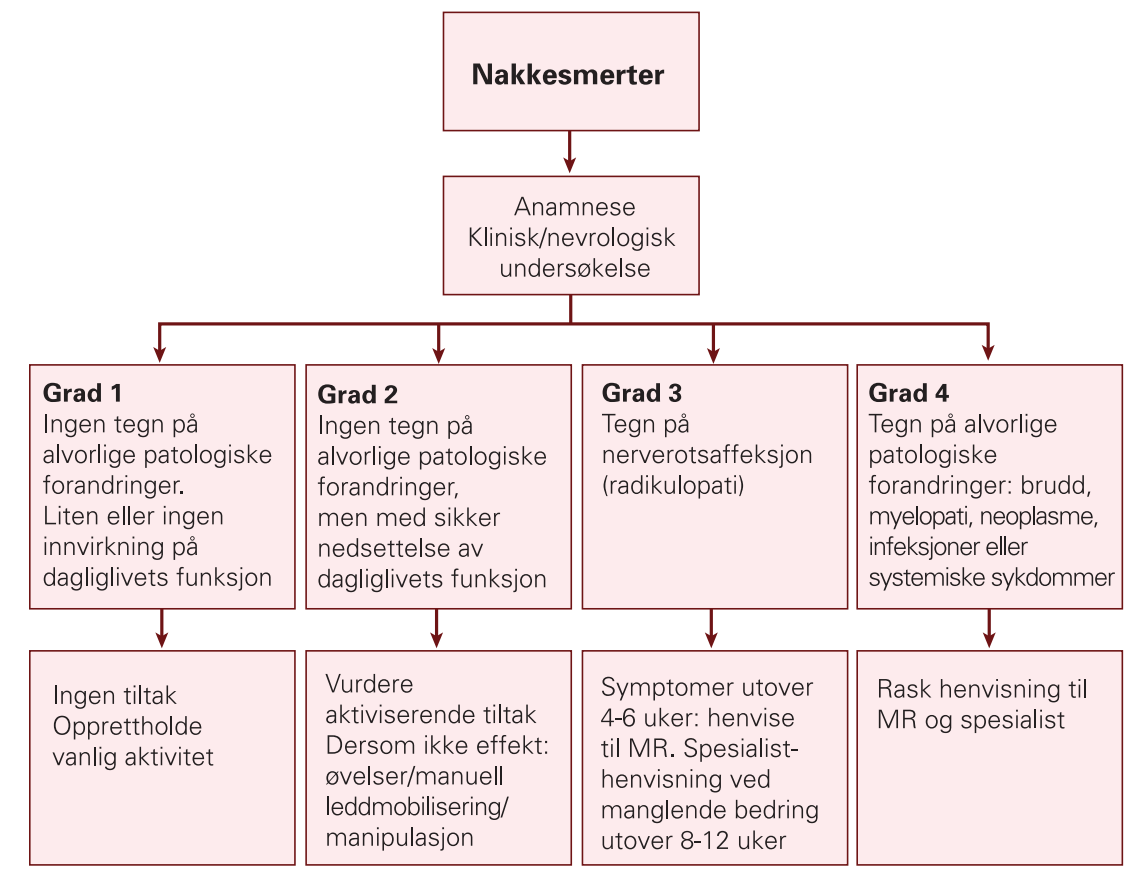

Figur 2 Håndtering av pasienter med nakkesmerter ut fra foreslått inndeling i grad 1-4

assosiert med lavere sosioøkonomisk status (31) og gir økt sannsynlighet for uførhet (32). Dette understreker betydningen av bred tverrfaglig tilnærming overfor noen av disse pasientene, spesielt der hvor aktiviserende tiltak ikke har lyktes.

\section{Mistenkt nerverotsaffeksjon}

Cervikal nerverotsaffeksjon skal primært behandles uten kirurgi dersom det ikke er meget sterke smerter eller uttalt parese. Flertallet av pasientene vil oppleve symptombedring uten operasjon i løpet av de første ukene, men det naturlige forløpet av cervikal nerverotsaffeksjon er ikke godt dokumentert. Det er beskrevet 60-90\% komplett remisjon av smerter ved langtidsobservasjon (12). I akuttfasen anbefales avlastning av nakken ved å unngå smerteprovoserende bevegelser, særlig ekstensjon. Lett traksjonsbehandling kan forsøkes. Transforaminal steroidinjeksjon har vært forsøkt, men effekten er usikker. Behandlingen utføres ikke i Norge (12).

Ved betydelige smerter med varighet over 8-12 uker som gir nedsatt livskvalitet og er til hinder for deltakelse i arbeidslivet, kan det foreligge operasjonsindikasjon. Det finnes en rekke randomiserte studier der ulike operasjonsteknikker er sammenliknet, men bare én der kirurgi er sammenliknet med ikke-operativ behandling (33). I denne studien fant man ingen sikker forskjell mellom kirurgi og ikke-operativ behandling, men den har vesentlige mangler og deltakerne hadde meget lang symptomvarighet. Gevinsten av kirurgi ser ut til å være rask bedring av smertene, langtidseffekten sammenliknet med ikke-operativ behandling er mer usikker $(11,13)$. Et vesentlig spørsmål å stille en pasient med cervikal nerverotsaffeksjon blir derfor om smertene er akseptable i et tidsperspektiv for bedring på 6-12 måneder. Konsekvensene av langvarig sykmelding må også veie tungt når man vurderer operativ behandling.

I dag er det vanlig å operere cervikal nerverotsaffeksjon fra ventralsiden. Skiven ekstirperes og nerveroten dekomprimeres ved at prolapset fjernes eller nerverotskanalen åpnes. Etter dekompresjonen settes det inn et bur (cage) som opprettholder avstanden mellom virvlene og stimulerer til beinvekst. De to virvlene vokser sammen til én blokkvirvel. Ved bruk av bur er det ikke nødvendig å ta bein fra hoftekammen, slik man gjorde tidligere, og pasienten trenger ikke stiv halskrage etter operasjonen. Det er også mulig å fjerne et cervikalt prolaps bakfra via en fasettektomi, der deler av fasettleddet fjernes.

Behandling av cervikal nerverotsaffeksjon kan i dag gjøres som dagkirurgi. Pasientene har lite smerter etter inngrepet, men flertallet opplever en viss grad av dysfagi noen dager/uker etter operasjonen. Komplikasjonsraten henger sammen med pasientens alder og antall nivåer operert, men ved operasjon på ett nivå er komplikasjoner relativt sjeldent og inntreffer i totalt ca. $5 \%$ av 
tilfellene (11). Skade av ryggmarg eller nerverot er meget uvanlig.

De siste årene er cervikal skiveprotese introdusert som et alternativ til innsetting av bur. Protesen skal teoretisk kunne opprettholde bevegeligheten mellom virvlene etter operasjonen. Behandlingen anses som eksperimentell, og langtidsresultatene er ukjent. Det foregår for tiden en norsk randomisert multisenterstudie der skiveprotese blir sammenliknet med innsetting av bur.

\section{Status for nakkeforskningen}

Den norske nakkeforskningen, med unntak av forskning på kronisk nakkeslengssyndrom, er beskjeden. Den drives av små og sårbare miljøer, og det finnes ingen koordinerende plan. Det foreligger heller ikke noe nasjonalt register for å evaluere effekten av ulike typer behandling, men et nasjonalt nakkeregister er under planlegging. Sett i lys av det store samfunnsmessige problem som denne gruppen pasienter representerer, har forskningsmidlene vært meget små. Utfordringene ligger i å koordinere de eksisterende miljøene, etablere kliniske registre, kartlegge prediktorer og grunnlag for subklassifisering og evaluere effekten av målrettede intervensjoner.

\section{Avslutning}

Diagnostikk og utredning av nakkesmerter er først og fremst rettet mot å utelukke nerverotsaffeksjon eller alvorlig sykdom (røde flagg). De uspesifikke nakkesmertene (grad $1 \mathrm{og} \operatorname{grad} 2$ ) er fortsatt en utfordring, og kunnskapen om hvilke tilstander som kan ligge bak er usikker. Ulike generatorer for smerte er foreslått, men mye forskning gjenstår før dette er kartlagt. Mangelen på kliniske retningslinjer gjør at denne artikkelen må betraktes som et første skritt på veien mot nasjonale retningslinjer. Mangelen på publikasjoner av høy kvalitet innen dette feltet gjør behandling av nakkesmerter krevende. Det er åpenbart behov for en innsats på området, og det bør føre til mer forskning.

Oppgitte interessekonflikter: Ingen

\section{Litteratur}

1. The burden of musculoskeletal conditions at the start of the new millennium. World Health Organ Tech Rep Ser 2003; 919: 1-218.
2. Nordin M, Carragee EJ, Hogg-Johnson S et al. Assessment of neck pain and its associated disorders: results of the Bone and Joint Decade 2000-2010 Task Force on Neck Pain and Its Associated Disorders. Spine (Phila Pa 1976) 2008; 33 (suppl): S101-22.

3. Hogg-Johnson S, van der Velde G, Carroll LJ et al. The burden and determinants of neck pain in the general population: results of the Bone and Joint Decade 2000-2010 Task Force on Neck Pain and Its Associated Disorders. Spine (Phila Pa 1976) 2008; 33 (suppl): S39-51.

4. Natvig B, Nessøy I, Bruusgaard D et al. Muskel- og skjelettplager i en befolkning. Forekomst og lokalisasjon. Tidsskr Nor Lægeforen 1994; 114: 323-7.

5. Ihlebaek C, Eriksen HR, Ursin H. Prevalence of subjective health complaints (SHC) in Norway. Scand J Public Health 2002; 30: $20-9$.

6. Svebak S, Hagen K, Zwart J-A. One year prevalence of chronic musculoskeletal pain in a large adult Norwegian county population. Relation with age and gender. The HUNT study. Journal Of Musculoskeletal Pain 2006: 14: $21-8$

7. Hagen K, Svebak S, Zwart J-A. Incidence of musculoskeletal complaints in a large adult Norwegian county population. The HUNT Study. Spine (Phila Pa 1976) 2006; 31: 2146-50.

8. Trygdestatistisk årbok 2005. Oslo: Rikstrygdeverket, 2005

9. Guzman J, Haldeman S, Carroll LJ et al. Clinical practice implications of the Bone and Joint Decade 2000-2010 Task Force on Neck Pain and Its Associated Disorders: from concepts and findings to recommendations. Spine (Phila Pa 1976) 2008; 33 (suppl): S199-213.

10. Hurwitz EL, Carragee EJ, van der Velde $G$ et al. Treatment of neck pain: noninvasive interventions: results of the Bone and Joint Decade 2000-2010 Task Force on Neck Pain and Its Associated Disorders. Spine (Phila Pa 1976) 2008; 33 (suppl): S123-52.

11. Carragee EJ, Hurwitz EL, Cheng I et al. Treatment of neck pain: injections and surgical interventions: results of the Bone and Joint Decade 2000-2010 Task Force on Neck Pain and Its Associated Disorders. Spine (Phila Pa 1976) 2008; 33 (suppl): S153-69.

12. Yonenobu K. Cervical radiculopathy and myelopathy: when and what can surgery contribute to treatment? Eur Spine J 2000; 9: 1-7.

13. Matz PG, Holly LT, Groff MW et al. Indications for anterior cervical decompression for the treatment of cervical degenerative radiculopathy. J Neurosurg Spine 2009; 11: 174-82.

14. Spurling RG, Scoville WB. Lateral rupture of the cervical intervertebral discs: a common cause of shoulder and arm pain. Surg Gynecol Obstet 1944; 78: $350-8$.

15. Falla D, Jull G, Hodges PW. Feedforward activity of the cervical flexor muscles during voluntary arm movements is delayed in chronic neck pain. Exp Brain Res 2004; 157: 43-8.

16. Woodhouse A, Vasseljen O. Altered motor control patterns in whiplash and chronic neck pain. BMC Musculoskelet Disord 2008: 9: 90.

17. Bogduk N. The neck and headaches. Neurol Clin 2004; 22: $151-71$, vii.

18. van der Windt DA, Koes BW, de Jong BA et al. Shoulder disorders in general practice: incidence. patient characteristics, and management. Ann Rheum Dis 1995; 54: 959-64.
19. Tong HC, Haig AJ, Yamakawa K. The Spurling test and cervical radiculopathy. Spine (Phila Pa 1976) 2002; 27: $156-9$.

20. Karjalainen KA, Malmivaara A, van Tulder MW et al. Multidisciplinary biopsychosocial rehabilitation for neck and shoulder pain among working age adults. Cochrane Database Syst Rev 2009; nr. 2 CD002269

21. Jull G, Trott P, Potter $\mathrm{H}$ et al. A randomized controlled trial of exercise and manipulative therapy for cervicogenic headache. Spine (Phila Pa 1976) 2002; 27: 1835-43.

22. Hoving JL, Koes BW, de Vet HC et al. Manual therapy, physical therapy, or continued care by a general practitioner for patients with neck pain. A randomized, controlled trial. Ann Intern Med 2002; 136: 713-22.

23. Revel M, Minguet M, Gregoy $P$ et al. Changes in cervicocephalic kinesthesia after a proprioceptive rehabilitation program in patients with neck pain: a randomized controlled study. Arch Phys Med Rehabil 1994: 75: 895-9.

24. Trinh K Graham N, Gross A et al. Acupuncture for neck disorders. Spine (Phila Pa 1976) 2007; 32 : 236-43.

25. Gur A, Sarac AJ, Cevik R et al. Efficacy of $904 \mathrm{~nm}$ gallium arsenide low level laser therapy in the management of chronic myofascial pain in the neck: a double-blind and randomize-controlled trial. Lasers Surg Med 2004; 35: 229-35.

26. van der Velde G, Hogg-Johnson S, Bayoumi AM et al. Identifying the best treatment among common nonsurgical neck pain treatments: a decision analysis. Spine (Phila Pa 1976) 2008; 33 (suppl): S184-91.

27. Carroll LJ, Hogg-Johnson S, van der Velde G et al. Course and prognostic factors for neck pain in the general population: results of the Bone and Joint Decade 2000-2010 Task Force on Neck Pain and Its Associated Disorders. Spine (Phila Pa 1976) 2008; 33 (suppl): S75-82.

28. Kamaleri Y, Natvig B, Ihlebaek CM et al. Number of pain sites is associated with demographic, lifestyle, and health-related factors in the general population. Eur J Pain 2008; 12: 742-8.

29. Holth HS, Werpen HK, Zwart JA et al. Physical inactivity is associated with chronic musculoskeletal complaints 11 years later: results from the Nord-Trøndelag Health Study. BMC Musculoskele Disord 2008; 9: 159

30. Hagen K, Einarsen C, Zwart JA et al. The co-occurrence of headache and musculoskeletal symptoms amongst 51050 adults in Norway. Eur J Neurol 2002; 9: 527-33.

31. Hagen K, Zwart JA, Svebak S et al. Low socioeconomic status is associated with chronic musculoskeletal complaints among 46,901 adults in Norway. Scand J Public Health 2005; 33: 268-75

32. Kamaleri Y, Natvig B, Ihlebaek CM et al. Does the number of musculoskeletal pain sites predict work disability? A 14-year prospective study. Eur J Pain 2009; 13: 426-30

33. Persson LC, Carlsson CA, Carlsson JY. Long-lasting cervical radicular pain managed with surgery, physiotherapy, or a cervical collar. A prospective, randomized study. Spine (Phila Pa 1976) 1997; 22: $751-8$.

Manuskriptet ble mottatt 27.10. 2009 og godkjent 26.8. 2010. Medisinsk redaktør Are Brean. 